\title{
PAF104, a Synthetic Peptide to Control Rice Blast Disease by Blocking Appressorium Formation in Magnaporthe oryzae
}

\author{
Aarón Rebollar and Belén López-García \\ Department of Molecular Genetic, Centre for Research in Agricultural Genomics (CRAG) CSIC-IRTA-UAB-UB, CRAG Building, \\ Campus UAB, Bellaterra (Cerdanyola del Vallés) 08193 Barcelona, Spain
}

Submitted 20 April 2013. Accepted 22 May 2013.

\begin{abstract}
Magnaporthe oryzae is the most devastating pathogen of rice and the main cause of crop losses worldwide. The successful management of blast disease caused by this fungus is a clear necessity. The synthetic peptide PAF104 has been characterized by its inhibition of $M$. oryzae appressorium formation on hydrophobic surfaces. Growth and the ability of conidia to germinate was not affected by PAF104, indicating the lack of toxicity on fungal conidia. The addition of the cutin monomer 1,16-hexadecanediol does not interfere with the inhibitory effect of PAF104 on in vitro hydrophobic surfaces. On the other hand, inhibition of appressorium formation by PAF104 was nullified by the exogenous addition of cAMP. Our results suggest that PAF104 affects the Pmk1 pathway by repression of the gene expression of $M o M S B 2$, which encodes a sensing surface protein, and the mitogen-activated protein/extracellular signal-regulated kinase kinase kinase MST11. The pathogenicity of M. oryzae was reduced after PAF104 treatment specifically blocking appressorium formation. Our results support PAF104 as a promising compound to control rice blast disease by blocking a specific target related to appressorium formation, a process essential for infection of rice leaves. Moreover, PAF104 is proposed as a lead compound to develop novel specific fungicides with improved properties.
\end{abstract}

Rice (Oryza sativa) is the staple food for a large part of the world's population. The blast disease caused by the fungus Magnaporthe oryzae (anamorph Pyricularia grisea) is one of the most devastating diseases of cultivated rice (Dean et al. 2012; Wilson and Talbot 2009). Managing rice blast requires the integration of many strategies, such as cultural strategies for prevention, use of resistant varieties, biological control, and chemical fungicides (Brent and Hollomon 2007; Wang and Valent 2009). However, the control of rice blast disease by the development of resistant varieties harboring a resistance $(R)$ gene is not completely successful due, in part, to the high degree of pathogenic variability of $M$. oryzae and the large number of fungal races encountered in the field population (Ebbole 2007). Currently, chemical treatment with fungicides is the most

Corresponding author: Belén López-García;

E-mail: belen.lopez@cragenomica.es

* The $e$-Xtra logo stands for "electronic extra" and indicates that two supplementary figures and one supplementary table are published online and that Figures 5, 6, and 7 appear in color online.

C 2013 The American Phytopathological Society commonly used method to control rice blast disease, including probenazole, which acts via activation of natural defense mechanisms in susceptible rice plants. However, M. oryzae isolates that overcome chemical fungicides have been characterized, e.g., the development of a population resistant to carpropamid, which is a dehydratase inhibitor in melanin biosynthesis (MBI-D), or to strobilurin-related Qo inhibitors, which inhibit respiration (Avila-Adame and Koller 2003; Takagaki et al. 2004). In addition to the loss of effectiveness, negative long-term repercussions on human health and the environment have resulted in restrictions on the use of some important fungicides (Brent and Hollomon 2007). The legislation on the use of fungicides is becoming more restricted; many chemical fungicides are being reviewed for safety and efficacy and it's possible some of them may be deregistered as dangerous to humans or the environment (U.S. Environmental Protection Agency, The Center for Health and Wellness, European Food Safety Authority websites). This scenario has propelled the search for, one or both, alternative disease management strategies or safer antifungal agents that could substitute or decrease the quantity of fungicides currently in use (Brent and Hollomon 2007; Knight et al. 1997; Ragsdale 2000). One important requirement for new fungicides is the selectivity of their mode of action, being more pathogen-specific and with lower unspecific toxicity. Specific compounds could be identified by screening for molecules that specifically block infection-related processes more than they inhibit vegetative hyphal growth.

$M$. oryzae infect all foliar tissues. Moreover, M. oryzae infection of the panicle can lead to complete loss of grain. This fungus is a very effective hemibiotrophic pathogen that passes through a set of well-defined developmental steps during leaf infection, including the formation of a specialized structure called the appressorium, which is required to penetrate the host surface (Ebbole 2007; Khang et al. 2010; Wang and Valent 2009; Wilson and Talbot 2009). Although M. oryzae has traditionally been considered a foliar pathogen, more recently, it has been shown that this fungus colonizes rice roots (CamposSoriano and San Segundo 2009; Sesma and Osbourn 2004). The different stages involved in the pre-penetration phase of M. oryzae, i.e., adhesion, conidia germination and appressorium formation, and maturation have been extensively studied (Campos-Soriano and San Segundo 2009; Liu et al. 2011; Tucker et al. 2010; Wilson and Talbot 2009). Inhibitors of these specific developmental stages could be of great interest as substitutes for fungicides currently in use, and they could also contribute to general knowledge about the plant infection process of $M$. oryzae. In particular, the identification of compounds effective for inhibition of signaling pathways involved in $M$. 
oryzae appressorium formation is of special interest. In this regard, the current fungicides tricyclazole (MBI-R) and carpropamid (MBI-D) act to block host penetration by inhibiting melanization of the appressorium (Fungicide Resistance Action Committee website, FRAC Code List 2013).

Appressorium development is a complex morphogenetic process regulated by multiple external signals, such as surface hydrophobicity, hardness, cutin monomers, and leaf waxes, and different transduction pathways, including mitogen-activated protein (MAP) kinases Pmk1 and Mps1 and cAMP-dependent signaling pathways (Hamel et al. 2012; Jin et al. 2013; Lengeler et al. 2000; Wilson and Talbot 2009). While cAMP signaling controls surface recognition and the initiation of appressorium formation, late stages of appressorium formation, penetration, and infectious growth are regulated by the Pmk1 and Mps1 MAP kinase pathways (Wilson and Talbot 2009). In addition to these important pathways, several proteins have been characterized in $M$. oryzae as critical sensors to recognize different external signals, including the hydrophobin Mpg1, the $G$ protein-coupled receptor Pth11, and the recently identified proteins MoMsb2 (a surface mucin protein) and MoSho1 (a membrane sensor) (DeZwaan et al. 1993, Liu et al. 2011; Talbot et al. 1993).

Antimicrobial peptides (AMP) have emerged as promising compounds with important biotechnological applications in plant disease protection. Numerous natural and synthetic AMP have been identified based on their direct inhibiting effect on the growth of a broad range of microorganisms (López-García et al. 2012b; Marcos et al. 2008; Zasloff 2002). The fast and efficient action of AMP against microbes, their low risk of resistance emergence, and low toxicity to nontarget cells have made them a promising alternative to common antibiotics and fungicides in the fight against pathogen infection (Hancock and Sahl 2006; López-García et al. 2012b; Marcos et al. 2008; Montesinos et al. 2012).

A collection of small cationic tryptophan-rich AMP, the socalled PAF peptides, have been generated and characterized by their potent antifungal activity against several microorganisms (López-García et al. 2002; Muñoz et al. 2007). Some of these peptides show reduced toxicity against bacteria and they are not cytotoxic to human red blood cells. The lead peptide PAF26 is a synthetic hexapeptide that was previously identified by a combinatorial screening against the filamentous fungus Penicillium digitatum (López-García et al. 2002). This peptide is not toxic to human cells (López-García et al. 2007). A complete study on its mode of action showed that the peptide is internalized by fungal cells at subinhibitory concentrations and this cell-penetration is required for cell death (Muñoz et al. 2012). A transcriptome study on Saccharomyces cerevisiae has identified cell components and intracellular pathways that modulate its sensitivity, suggesting that PAF26 has intracellular targets (Carmona et al. 2012; López-García et al. 2010). Together with PAF26, a set of D-amino acid-hexapeptides,

Table 1. Peptide amino acid sequences analyzed in this study

\begin{tabular}{ll}
\hline Peptide & \multicolumn{1}{c}{ Sequence $^{\text {a }}$} \\
\hline PAF26D & AcNH-rkkwfw-CONH \\
PAF26L & $\mathrm{NH}_{2}-\mathrm{RKKWFW-COOH}_{2}$ \\
PAF34D & AcNH-rkwlfw-CONH \\
PAF34L & AcNH-RKWLFW-CONH \\
PAF42D & AcNH-wrkkwfw-CONH \\
PAF104 (PAF42L) & $\mathrm{NH}_{2}$-WRKKWFW-COOH \\
\hline
\end{tabular}

${ }^{a}$ Following standard rules, D-stereoisomers of amino acids are noted in lowercase and L-stereoisomers in uppercase. Where indicated, the peptides are acetylated at the $\mathrm{N}$ terminus ( $\mathrm{AcNH}-$ ) and amidated at the $\mathrm{C}$ terminus $\left(-\mathrm{CONH}_{2}\right)$. including PAF34D, with different profiles of antimicrobial activity was identified (López-García et al. 2002). Moreover, the elongation of the PAF26 sequence allowed us to identify a set of D-amino acid-heptapeptides, in particular, PAF42D, that show remarkably more activity against the phytopathogen M. oryzae (Muñoz et al. 2007).

In this work, we have identified a synthetic PAF26-derived peptide called PAF104, which specifically reduces the appressorium formation of $M$. oryzae on a hydrophobic polystyrene surface and on rice leaves. The peptide does not affect the germination and vegetative growth of the fungus, indicating the lack of toxicity on fungal conidia. Moreover, the fungus treated with PAF104 shows reduced pathogenicity on rice, i.e., PAF104 reduces the development of the rice blast disease by blocking the appressorium formation of M. oryzae.

\section{RESULTS}

\section{PAF104 inhibits appressorium formation in M. oryzae.}

We initially investigated whether some of the short PAF peptides have a specific effect on appressorium formation in $M$. oryzae. Table 1 shows the amino acid sequences of the PAF peptides tested, in which peptides synthesized with either all L- or all D-amino acids are included. An assay was set up to quantify the appressorium formation after peptide treatment (described below). Using this assay, the heptapeptide sequence WRKKWFW was found to show a remarkable inhibition activity on appressorium formation in both the L- and D-amino acid peptides (Fig. 1A). Considering the advantage of using a peptide synthesized with natural L-amino acids in a future potential application to control rice blast disease, we selected the peptide PAF104 for further study. The inhibitory activity of PAF104 on appressorium formation in germinating $M$. oryzae conidia is illustrated in Figure 1B.

To characterize the appressorium-blocking activity of PAF104 in more detail, we studied the effect of different concentrations of the peptide on the appressorium formation of two M. oryzae isolates, PR9 and Guy11. We evaluated the effect of PAF104 at an initial stage of the appressorium formation, i.e., $6 \mathrm{~h}$ after conidia germination, when the appressorium is differentiated from the tip of the germ tube. We observed a reduction of appressorium formation that correlated with an increase of peptide concentration for both isolates (Fig. 1C). A low concentration of PAF104 $(5 \mu \mathrm{M})$ showed a light effect on appressorium formation after a 6-h incubation. Approximately $50 \%$ of conidia of the PR9 isolate developed appressorium at $10 \mu \mathrm{M}$ of PAF104, and more than $80 \%$ of conidia were unable to develop appressorium in the presence of $30 \mu \mathrm{M}$ of PAF104. Evaluation of the inhibitory activity of PAF104 at a later stage when the mature appressorium is observed, i.e., $24 \mathrm{~h}$ after inoculation of conidia on a hydrophobic surface, shows similar results. For example, 85 and $25 \%$ of developed mature appressoria were observed after $24 \mathrm{~h}$ of incubation with 5 and $20 \mu \mathrm{M}$ of PAF104, respectively (Fig. 1C).

Several compounds have been described as inductors of appressorium formation on hydrophilic surfaces on which germinating conidia failed to develop appressoria, such as the cutin monomers 1,16-hexadecanediol or a regulator of appressorium morphogenesis cAMP (Wilson and Talbot 2009). In this work, the effect of these inductors on the inhibitory activity of PAF104 was evaluated. M. oryzae was placed on a hydrophilic (Fig. 2A) or hydrophobic surface (Fig. 2B), along with PAF104 alone or in the presence of either cAMP or 1,16hexadecanediol. Appressorium formation was quantified at $6 \mathrm{~h}$ postinoculation in different conditions, as previously described. The results shown in Figure 2 correspond to a representative assay with the Guy11 isolate (similar results were obtained with 
the PR9 isolate; data not shown). Our data confirm that appressorium formation was induced by the addition of $2.4 \mathrm{mM}$ cAMP or $10 \mu \mathrm{M}$ 1,16-hexadecanediol on hydrophilic surfaces (Fig. 2A). Moreover, the addition of 1,16-hexadecanediol did not affect the appressorium inhibition activity of PAF104, although the formation of appressoria was restored after the addition of cAMP. The same behavior also occurs on hydrophobic surfaces as shown in Figure 2B. Around $30 \%$ of $M$. oryzae conidia developed appressoria on a hydrophobic sur-
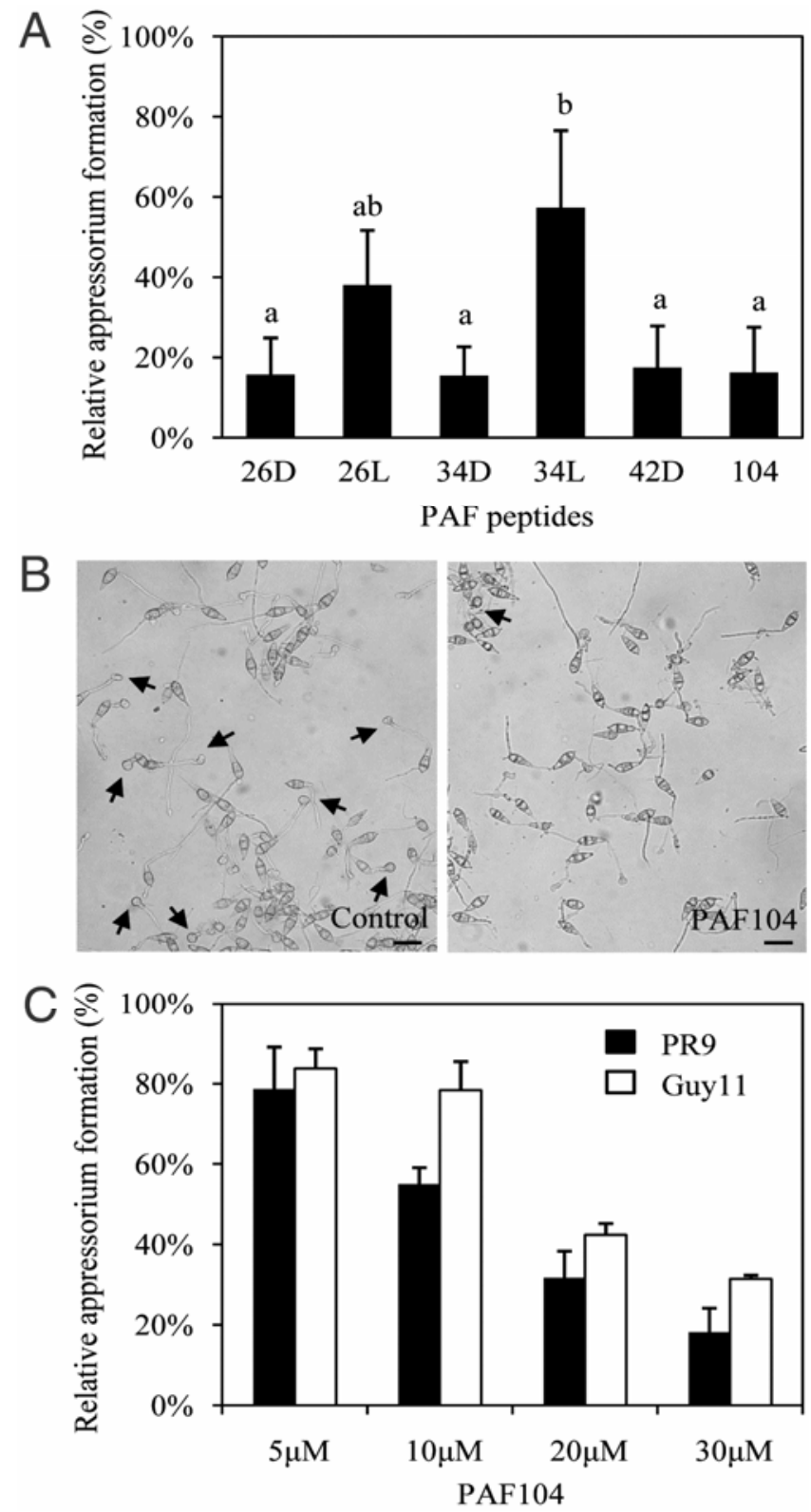

Fig. 1. Effect of PAF peptides on Magnaporthe oryzae appressorium formation on a hydrophobic surface. A, Relative appressorium formation in $M$. oryzae PR9 treated with PAF peptides. Appressorium formation was visualized after $6 \mathrm{~h}$ of incubation with $30 \mu \mathrm{M}$ of each peptide at $28^{\circ} \mathrm{C}$. Bars labeled with the same letter do not differ at the $95 \%$ confidence (Tukey's honestly significant difference procedure). B, The effect of $20 \mu \mathrm{M}$ of PAF104 on the appressorium formation in M. oryzae PR9. Pictures were taken after $6 \mathrm{~h}$ of incubation. Arrows indicate some appressoria. Bar $=25 \mu \mathrm{m}$. C, Relative appressorium formation in $M$. oryzae PR9 (black bars) and Guy11 (white bars) isolates after $6 \mathrm{~h}$ of incubation with different concentrations of PAF104. Results in A and C are shown as mean values \pm standard deviation of the percentage of appressorium observed relative to the appressorium formed in the absence of peptide. face after treatment with $20 \mu \mathrm{M}$ PAF104. This inhibition was not affected by the addition of $10 \mu \mathrm{M}$ 1,16-hexadecanediol. However, the inhibitory activity of PAF104 can be overridden by cAMP. The addition of $2.4 \mathrm{mM}$ cAMP restored appressorium formation to almost the same level of the control sample without peptide treatment.

\section{PAF104 changes gene expression}

of the surface sensor $M S B 2$ and the mitogen-activated protein/extracellular signal-regulated kinase kinase (MEK) kinase MST11 involved in the Pmk1 pathway.

The results described above suggest that PAF104 may act upstream of the sites of action of cAMP, explaining the fact that its inhibition activity can be bypassed by this signaling molecule. In order to examine the effect of PAF104 on appressorium formation at the molecular level, representative genes involved in sensing surface signals and regulating appressorium formation through different pathways were selected (Supplementary Table S1; Fig. 3). Expression changes of selected genes were determined by reverse-transcription quantitative polymerase chain reaction (RT-qPCR) after peptide treatment (Fig. 4). These data show no important expression changes of genes involved in the activation of the cAMP pathway as MAC1 or PTH11. Interestingly, the expression of the gene MoMSB2 encoding a surface mucin protein was 4.5 times more repressed than control levels after exposure to $5 \mu \mathrm{M}$ of PAF104. At a higher concentration of the peptide $(20 \mu \mathrm{M})$, the
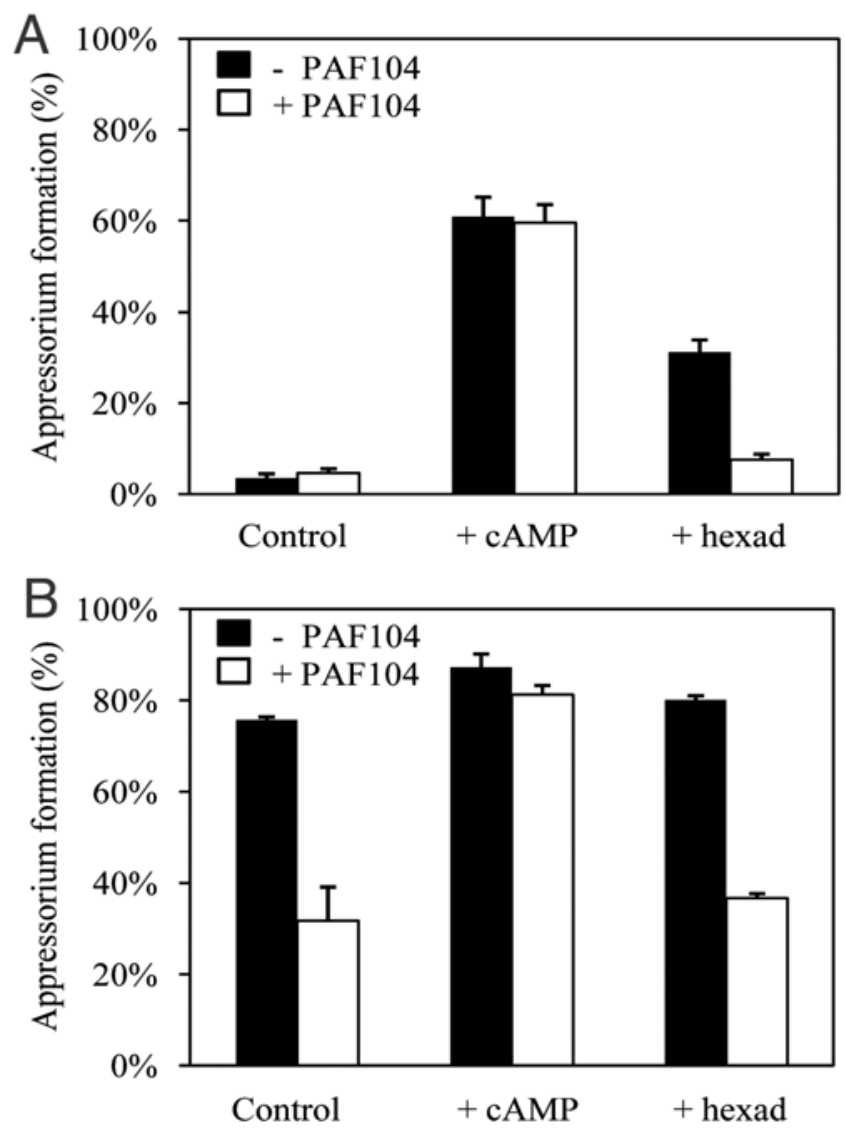

Fig. 2. Effect of two inductors of Magnaporthe oryzae appressorium formation on the inhibitory activity of PAF104. Conidia of M. oryzae Guy11 isolate were incubated alone (black bars) or with $20 \mu \mathrm{M}$ PAF104 (white bars) and in the absence or presence of either $2.4 \mathrm{mM}$ cAMP or $10 \mu \mathrm{M}$ 1,16-hexadecanediol for $6 \mathrm{~h}$ on a $\mathbf{A}$, hydrophilic or $\mathbf{B}$, hydrophobic surface. Results are shown as mean values \pm standard deviation of the percentage of conidia of $M$. oryzae Guy11 that form appressorium in each condition. 
repression of MoMSB2 was confirmed, although this effect was not concentration-dependent. The relative expression of MoMSB2 was similar at both peptide concentrations; $\log 2$ was $(-2.146 \pm 0.110)$ at $5 \mu \mathrm{M}$ PAF104 and $(-1.891 \pm 0.174)$ at 20 $\mu \mathrm{M}$. The protein MoMsb2, recently characterized in $M$. oryzae by Liu and co-workers (2011), plays an important role in sensing surface hydrophobicity and cutin monomers. Our qPCR analysis also revealed a minor repression of $\mathrm{MoSHO1}$, a gene encoding another sensor of external signals; in particular, MoSho1 recognizes rice leaf waxes (Liu et al. 2011). These authors show that MoMsb2 and MoSho1 may function upstream from the Pmk1 pathway. Consistently with their results, the expression of the MEK kinase MST11 was also found to be repressed in our analysis, although the $P M K 1$ expression level does not change after peptide treatment.

\section{PAF104 has no effect}

on adhesion, conidial germination, or mycelial growth.

The first steps of the $M$. oryzae infection cycle are adhesion of fungal conidia to the host surface and conidial germination. In this work, an adhesion assay on a hydrophobic polystyrene surface was conducted to evaluate if PAF104 reduced the number of conidia attached to the surface. A similar number of conidia of PR9 attached to the polystyrene surface after treatment with PAF104 (5 and $20 \mu \mathrm{M}$ ) compared with the control treatment without peptide. The percentage of attached conidia after treatment with $20 \mu \mathrm{M}$ PAF104 was $93.4 \pm 8.8$ (mean \pm standard deviation [SD]), considering $100 \%$ for control samples; the data was calculated as mean \pm SD from three independent experiments. In addition, the number of germinated conidia was quantified after peptide treatment and compared with that of the control treatment; the percentage of germinated conidia was $91.4 \pm 1.3$ for samples treated with $20 \mu \mathrm{M}$ PAF104 versus $92.7 \pm 0.6$ for the control. Our results showed that conidial germination remained unaffected at concentra- tions at which appressorium inhibition was observed, i.e., 20 $\mu \mathrm{M}$ PAF104.

Next, the effect of PAF104 on growth and development of $M$. oryzae mycelium was examined. The vegetative growth of M. oryzae PR9 isolate in liquid culture was unaffected by concentrations of PAF104 as high as $64 \mu \mathrm{M}$ (Supplementary Fig. S1).

Overall, these results indicate a specific effect of PAF104 on appressorium formation, i.e. the peptide reduces the ability of $M$. oryzae to form appressoria but does not affect either the adhesion of the conidia to hydrophobic surfaces, germination, or vegetative mycelial growth of the fungus $M$. oryzae.

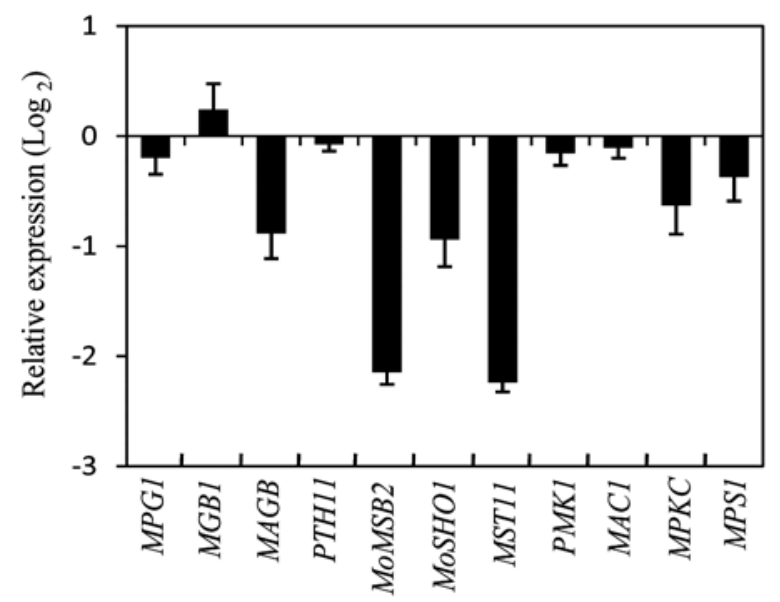

Fig. 4. Real time quantitative polymerase chain reaction analysis of gene expression changes after treatment with $5 \mu \mathrm{M}$ PAF104. The panel shows the mean relative expression \pm standard deviation ( $y$ axis) of each individual gene after $6 \mathrm{~h}$ of peptide treatment, as compared with the control treatment without peptide. The $E F 1 \alpha$ gene was used as constitutive reference gene.

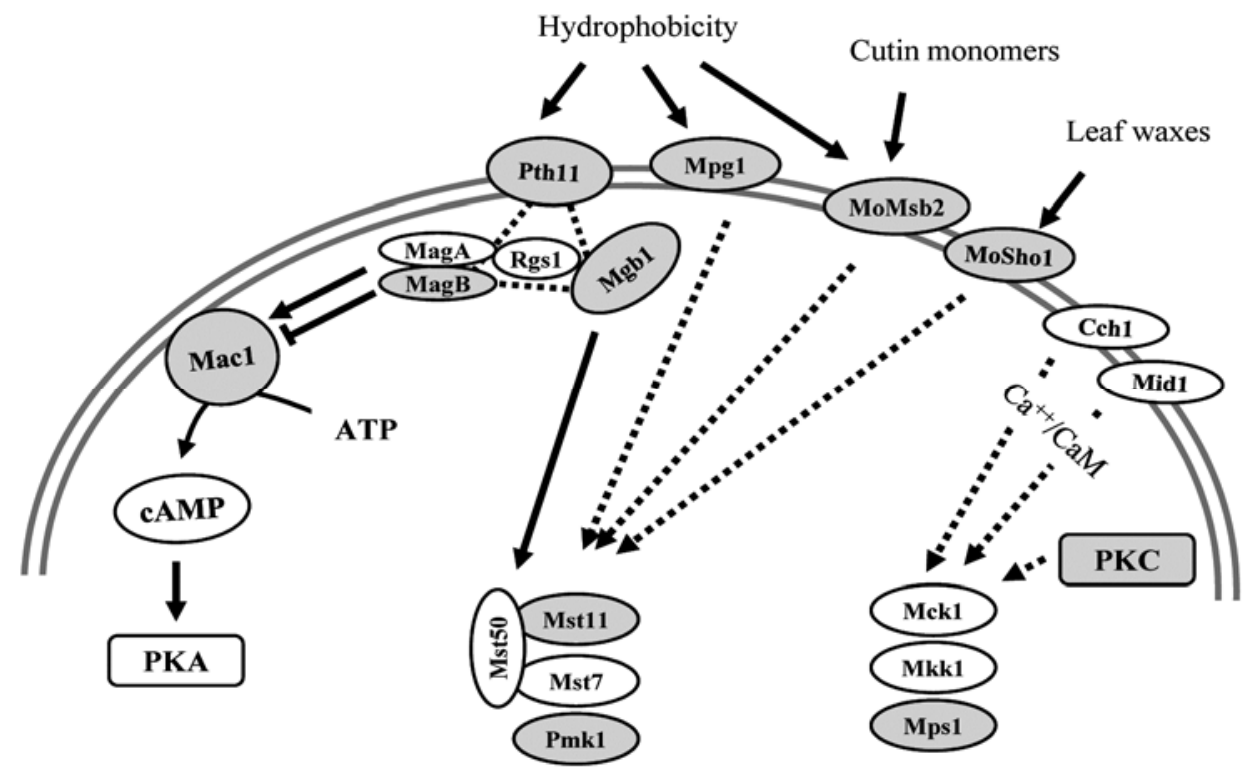

Fig. 3. Schematic view of the cyclic AMP (cAMP) response pathway and the Pmk1 and Mps1 mitogen-activated protein kinase (MAPK) pathways required for appressorium development in Magnaporthe oryzae (modified from Wilson and Talbot [2009] and Hamel and associates [2012]). cAMP signaling molecules are accumulated by adenylate cyclase Mac1 and allow the activation of the protein kinase A (PKA). The cAMP signaling pathway seems to be regulated by the Go-subunit proteins MagA and MagB, and the regulator of G protein signaling Rgs1 interacts with MagA during appressorium initiation. Activation of the Pmk1 pathway involves the G $\beta$-subunit protein Mgb1. Crosstalk with the cAMP pathway may occur through MagB. The G protein-coupled receptor Pth11 plays a role as the receptor for the cAMP response pathway and, perhaps, also the Pmk1 MAPK cascade. In addition to Pth11, the fungus response to environmental signals to induce appressorium formation by different proteins, including the hydrophobin Mpg1, the surface mucin protein MoMsb2, and the membrane sensor MoSho1. Activation of the Mps1 pathway may occur through calcium channel proteins (Cch1 or Mid1) or protein kinase $\mathrm{C}$ (PKC). Solid lines denote interactions supported by experimental evidence. Dotted lines indicate tentative interactions that require further experimental testing. The proteins encoded by the genes included in the expression analysis are colored in gray. 
PAF104 reduces the rice blast disease caused by $M$. oryzae.

The effect of PAF104 on appressorium formation and hyphal growth was examined in planta. For this, two M. oryzae strains expressing the green fluorescent protein $(g f p)$ gene were used. As previously published, expression of the $g f p$ gene did not affect the viability and pathogenicity of the M. oryzae transformants that were used in this work (Campos-Soriano and San Segundo 2009; Sesma and Osbourn 2004). First, the inhibitory effect of PAF104 on these GFP transformants was tested, showing a similar effect as on the wild-type fungal strains PR9 and Guy11. For example, at $20 \mu \mathrm{M}$ PAF104, the percentage of appressoria observed relative to control was $(42.2 \pm 2.0) \%$ and $(41.9 \pm 9.8) \%$ for Guy11 and $g f p$-Guy11 isolates, respectively. Detached leaves of rice cv. Senia were inoculated with fungal conidia as described below and were visualized by confocal microscopy at $6 \mathrm{~h}$ postinoculation (Fig. 5A; Supplementary Fig. S2). By $6 \mathrm{~h}$ postinoculation, a large number of green fluorescent germinating conidia formed appressoria were observed on the surface of rice leaves inoculated with either $g f p$-PR9 or $g f p$-Guy11 (Fig. 5Aa and b, e and f, respectively).

Next, we evaluated the effect of PAF104 on appressorium formation on the rice leaf surface. When drops of the conidial suspension were placed onto detached leaves along with 20 $\mu \mathrm{M}$ peptide, the number of appressoria observed was clearly reduced. As within the artificial hydrophobic polystyrene surface, the peptide is able to greatly reduce appressorium for- mation of the two fungal isolates assayed here, M. oryzae PR9 isolate (Fig. 5Ac and d) and Guy11 isolate (Fig. 5Ag and h).

The inoculation with both $g f p$-expressing $M$. oryzae isolates gave rise to a macroscopically visible lesion at 3 days after inoculation. Consistent with the confocal laser scanning microscopy (CLSM) analysis, disease severity was reduced after PAF104 treatment compared with fungal infection without treatment (Fig. 5B). To further investigate whether inhibition of appressorium formation could be correlated with reduced pathogenicity, blast resistance assays were conducted on young detached leaves of rice cv. Senia plants. Symptoms caused by inoculation with $M$. oryzae conidia in the presence or the absence of PAF104 was followed over time. Lesions caused by the fungus $M$. oryzae were observed at 3 days after inoculation; Figure 6A shows a representative assay with the Guy11 isolate. Under the same experimental conditions, a reduction in disease severity was observed when the fungus was treated with $20 \mu \mathrm{M}$ PAF104 as compared with the nontreated fungus. Similar results were obtained with the PR9 isolate (data not shown). Leaf lesions were also observed by light and fluorescence microscopy, which allowed in planta detection of the fungal mycelium. As depicted in the inset of Figure $6 \mathrm{~A}$, the lesions produced by inoculation with nontreated fungus showed bright GFP fluorescence. When the fungus was treated with PAF104, almost no blast disease lesions were visualized. We further quantified plant disease in leaves by determining the percentage of the leaf area affected by blast lesions
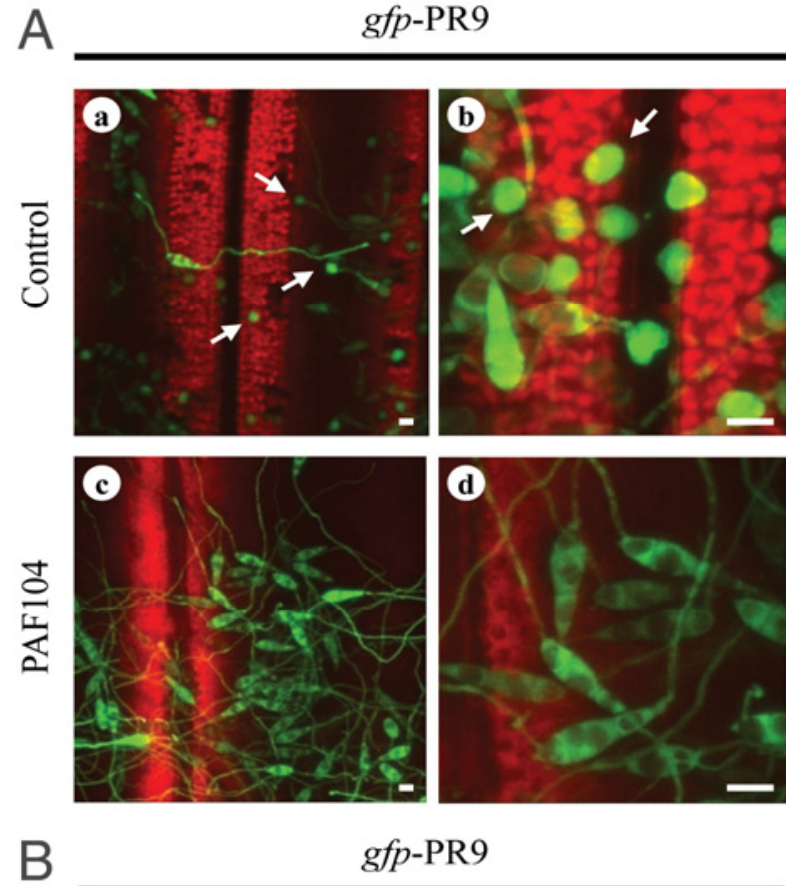

$g f p$-PR9

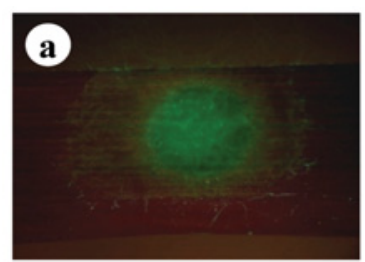

Control

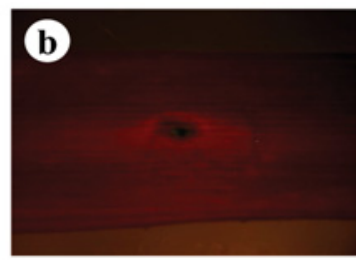

PAF 104

$g f p-G u y 11$
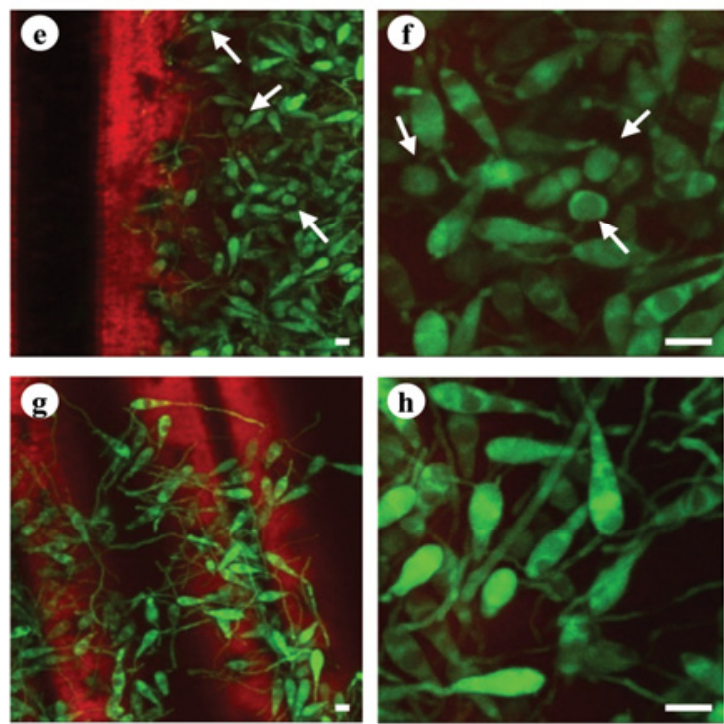

$g f p$-Guy11

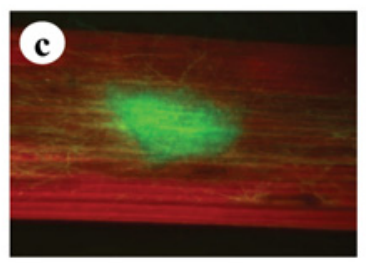

Control

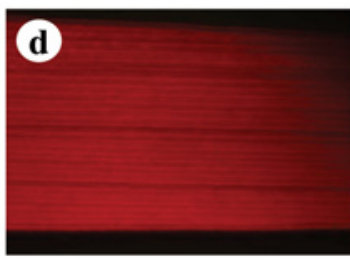

PAF104

Fig. 5. Appressorium formation and infection development on rice leaves inoculated with conidia of the gfp-expressing Magnaporthe oryzae PR9 and Guy11 isolates. A, Confocal laser scanning microscopy of rice leaves $6 \mathrm{~h}$ after inoculation with fungus in the absence (a and b, e and $\mathrm{f}$ ) or in the presence (c and $\mathrm{d}$, $\mathrm{g}$ and $\mathrm{h}$ ) of $20 \mu \mathrm{M}$ PAF104. Appressoria have formed at the penetration sites in the absence of peptide (arrows in a, b, e and f). Bar $=10 \mu \mathrm{m}$. B, Representative infection sites observed by fluorescent microscopy 3 days after inoculation with M. oryzae gfp-PR9 (a and b) and gfp-Guy11 (c and d) isolates alone (control) or treated with $20 \mu \mathrm{M}$ PAF104. 
(Fig. 6B). In agreement with visual inspections of infected leaves, this analysis confirmed that the development of the infection caused by $M$. oryzae on rice leaves was significantly reduced by PAF104 treatment.

PAF104 does not affect rice root colonization of $M$. oryzae.

$M$. oryzae has been reported to colonize rice roots under laboratory conditions (Campos-Soriano and San Segundo 2009; Sesma and Osbourn 2004). In order to evaluate if PAF104 affect root colonization, confocal microscopical observations of roots inoculated with $M$. oryzae ( $g f p$-PR9) treated or not with peptide were conducted. Conidia germinated on the rice root surface (Fig. 7). No differences were observed in root colonization when the fungus is treated with PAF104 relative to that of nontreated conidia. In fact, at $30 \mathrm{~h}$ after inoculation, the fungus had penetrated epidermal root cells (Fig. 7, arrows in $\mathrm{c}$ and $\mathrm{f}$ ) independently of the peptide treatment.

\section{DISCUSSION}

Important research efforts are being addressed to develop novel specific fungicides with lower unspecific toxicity in order to avoid some of the drawbacks of current fungicides. The identification and application of target-oriented antifungal compounds has been proposed as an environmentally sustainable strategy to control phytopathogen diseases (Brent
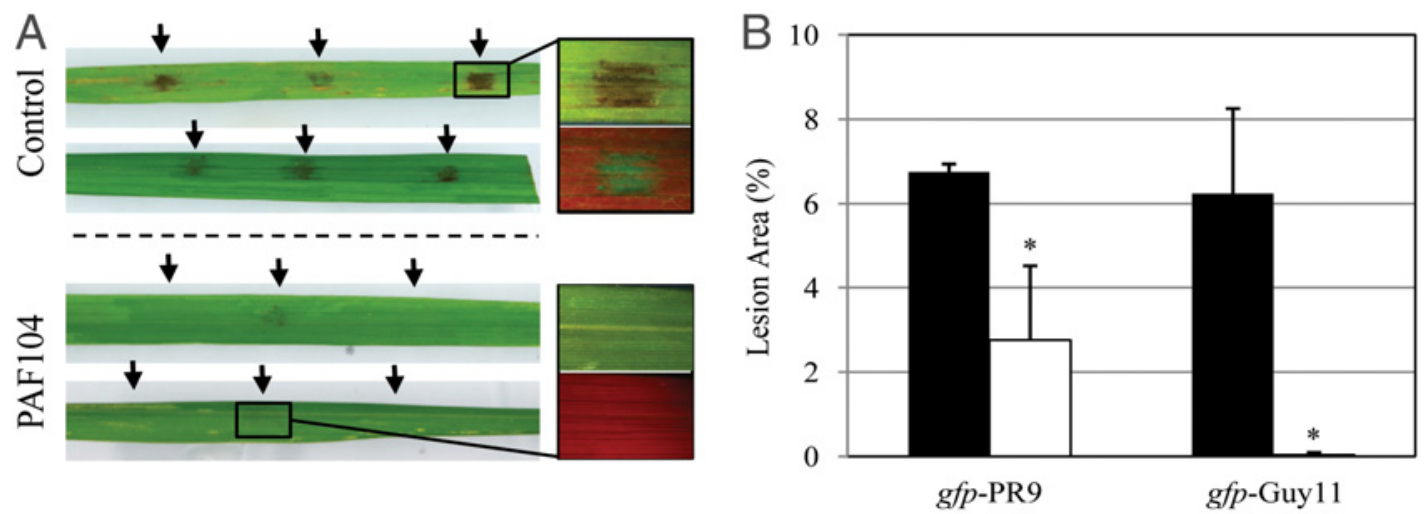

Fig. 6. Resistance to infection by the rice blast fungus Magnaporthe oryzae in rice cv. Senia plants. A, A representative experiment of infection of detached leaves with $g f p$-expressing Magnaporthe oryzae Guy11 isolate. Detached leaves were infected with a fungal solution adjusted to $5 \times 10^{6}$ conidia per milliliter from the isolate $g f p$-Guy11 nontreated (control) or treated with $20 \mu \mathrm{M}$ PAF104. Pictures were taken at 3 days after inoculation. Leaf lesions were also observed by light and fluorescent microscopy (inset images). B, Percentage of leaf area affected by blast lesions at 3 days postinoculation was determined using image analysis software Assess v. 2.0 for plant disease quantification. Results are shown as mean values \pm standard deviation of one representative experiment for each fungal isolate from at least two experiments with similar results. For both isolates, the treated sample differs from the control sample at the $95 \%$ confidence (analysis of variance).
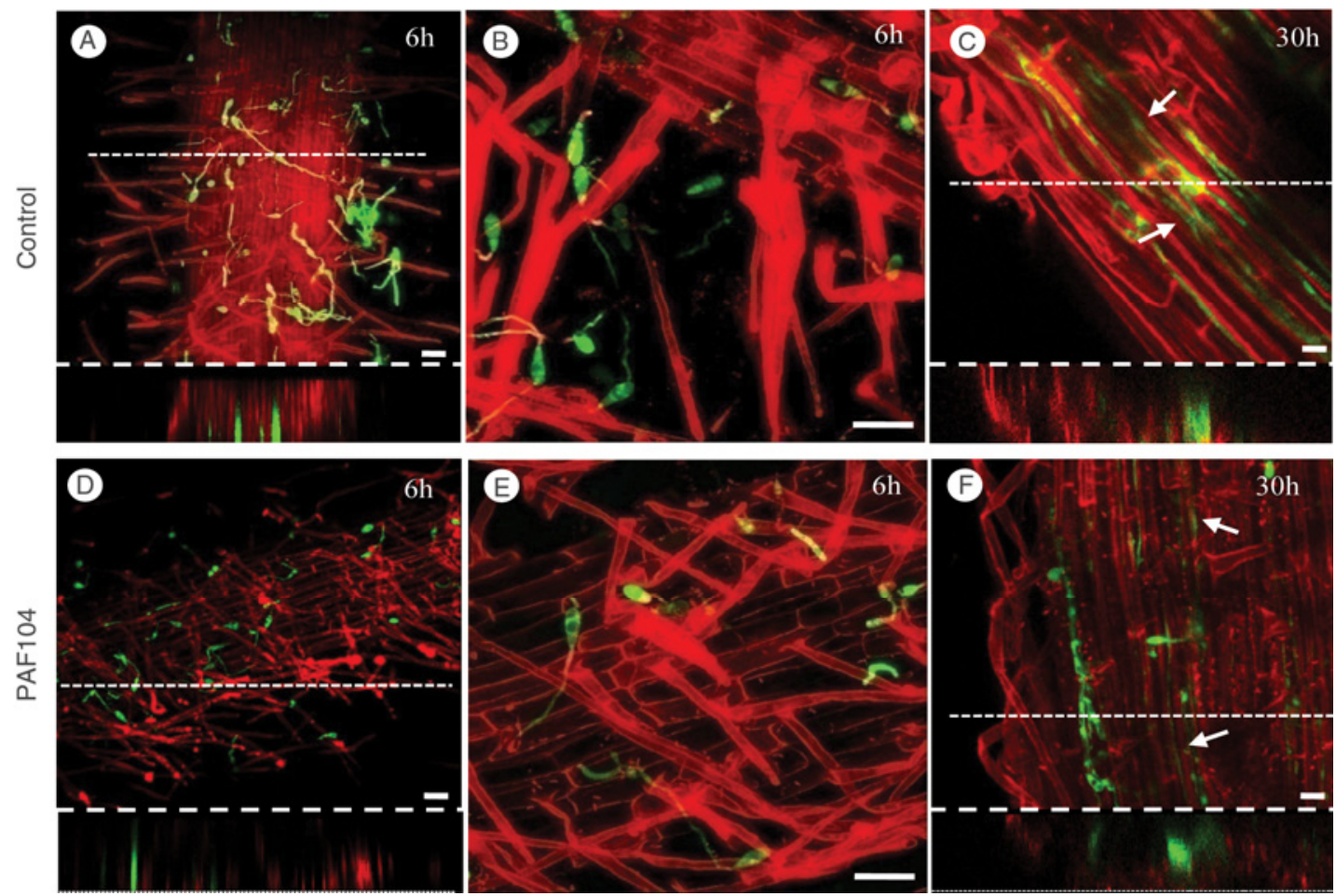

Fig. 7. Confocal laser scanning microscopy of rice roots inoculated with the gfp-expressing $\mathbf{A}$ to $\mathbf{C}$, Magnaporthe oryzae PR9 alone or $\mathbf{D}$ to $\mathbf{F}$, treated with $20 \mu \mathrm{M}$ PAF104 and stained with propidium-iodide to visualize the roots. Fungal conidia and hyphae in contact with rice roots $6 \mathrm{~h}$ after inoculation (A, B, D, and $\mathrm{E})$. Hyphae growing along the rice root $30 \mathrm{~h}$ after inoculation $(\mathrm{C}$ and $\mathrm{F})$; some epidermal cells have already been penetrated $(\operatorname{arrows})$. Bar $=10 \mu \mathrm{m}$. The dotted white lines in A, C, D, and F indicate the $x z$ axis presented in the lower parts of panels. 
and Hollomon 2007; Knight et al. 1997; Ragsdale 2000). Current chemical fungicides that inhibit conidial germination and mycelial growth normally have broad-spectrum activity and, probably, high relative toxicity. In this study, we have identified a small synthetic peptide, PAF104, that is effective for reducing the development of $M$. oryzae diseases on rice. Although PAF104 inhibited appressorium formation of $M$. oryzae, the ability of conidia to germinate and grow was not affected, suggesting that the peptide was not toxic to fungal conidia. In this regard, it has been proposed that compounds blocking a specific target required in infection are more pathogen-specific and, thus, will have low unspecific toxicity (Thines et al. 2004). PAF104 belong to the PAF series peptides previously characterized by their antifungal activity against several filamentous fungi but reduced toxicity against nontarget bacteria and yeast cells (López-García et al. 2002) and with low hemolysis compared with the lytic peptide melittin (Muñoz et al. 2007). Moreover, no cytotoxicity to human keratinocytes has been shown for one of these PAF peptides (PAF26) (López-García et al. 2007). Together with these previously published data regarding the toxicity of PAF peptides with primary sequence similarity, the results reported in this work suggest the lack of unspecific toxicity of PAF104. On the other hand, the peptide PAF42D, with analogous sequence to PAF104, showed growth-inhibitory activity against the phytopathogen $M$. oryzae with a MIC (minimum inhibitory concentration) value of $16 \mu \mathrm{M}$ (Muñoz et al. 2007). The growth inhibitory activity of PAF42D might be attributed to their possible higher resistance to protease degradation due to the D-amino acids sequence and the peptide ends modification by $\mathrm{N}$-terminal acetylation and $\mathrm{C}$-terminal amidation. However, the stability of PAF104 or PAF42D to protease degradation has not yet been tested. Similar experiments with another PAF peptide (PAF19) show that the peptide synthesized with L-amino acids is more susceptible to protease degradation than the peptide synthesized with D-amino acids (López-García et al. 2000). Further analyses of the unspecific toxicity and stability toward digestion by protease of PAF104 are needed.

Our experiments show a clear correlation between inhibition of appressorium formation by PAF104 in vivo (Fig. 5) and infection severity (Fig. 6). However, the peptide was not able to completely block appressorium formation on in vitro hydrophobic surfaces at the concentration used in in vivo appressorium formation and infection assays (i.e., $20 \mu \mathrm{M}$; Fig. 1C). The formation of nonfunctional appressorium or the activation of host resistance in response to peptide treatment might explain these results. In favor of the formation of nonfunctional appressorium, appressorium-like structures developed by hyphal tips were observed after treatment with PAF104 for 24 h (data not shown). Previous studies have shown that these appressorium-like structures have lower efficiency in plant penetration than appressoria formed by germ tubes (Kong et al. 2013).

On the other hand, the fungus is able to germinate and grow on the leaf surface, which is consistent with the lack of germination and growth inhibition by PAF104 in vitro. These data emphasize that PAF104 may not have unspecific toxicity, as noted above. Previous works suggested that chemical components present in rice leaves, such as cutin monomers including 1,16-hexadecanediol, may interfere with the inhibitory effect of some antifungal compounds (Oh and Lee 2000). Our data show that the addition of 1,16-hexadecanediol does not affect the inhibitory activity of PAF104 on in vitro hydrophobic surfaces, and consequently, this peptide blocks appressorium formation on rice leaves. Of interest, PAF104 is not able to block the colonization of $M$. oryzae on rice root under laboratory conditions. However, there is no evidence of infection of rice plants through $M$. oryzae colonization of roots in the field.

Currently, with the advent of high-throughput technologies, plant pathologists have made significant progress in understanding plant-pathogen interactions using model organisms such as M. oryzae (Kawahara et al. 2012; Liu et al. 2010; Mathioni et al. 2011; Soanes et al. 2012; Tucker et al. 2010; Wang and Valent 2009). This knowledge is useful to characterize the mode of action of different potential appressorium inhibitors. Our RT-qPCR analysis revealed the repression of MoMSB2 and MST11 gene expression. The transmembrane mucin protein Msb2 has been characterized as a surface sensor to induce appressorium formation in Ustilago maydis and $M$. oryzae (Lanver et al. 2010; Liu et al. 2011). Our results regarding the repression of the MoMSB2 gene expression by PAF104 suggest that the peptide might act in blocking the recognition of external signals, i.e. hydrophobicity and cutin monomers, required to induce appressorium formation. This hypothesis is consistent with the results obtained after the addition of the cutin monomer 1,16-hexadecanediol; that is, the PAF104 inhibition of appressorium formation cannot be nullified by the addition of this inductor. Moreover, the proposed mode of action of PAF104 is consistent with the idea that its inhibitory activity was bypassed by the addition of cAMP.

Liu and coworkers (2011) showed that the activation of Pmk1 was reduced in Momsb2 mutants, suggesting that MoMsb2 may function upstream from the Pmk1 pathway in $M$. oryzae, but $P M K 1$ expression was not affected in these mutants. According to these previous results, our data show that $P M K 1$ expression level does not change after peptide treatment, although PAF104 represses the expression of MST11. It has been demonstrated that mutants blocked in the Mst11-Mst7Pmk1 mitogen-activated protein kinase (MAPK) cascade fail to form appressoria and are nonpathogenic (Hamel et al. 2012; Zhao et al. 2005). Whether PAF104 treatment affects the activation of Pmk1 remains to be seen, and future research is being focused on the characterization of its mode of action in more detail.

On the other hand, we show that the expression level of the MAPK gene MPS1 does not change after PAF104 treatment. The mps 1 mutant has been characterized as significantly reduced in aerial hyphal growth and conidiation (Xu et al. 1998). The absence of MPS1 expression change by PAF104 is consistent with our results showing that the peptide does not affect the germination or vegetative mycelial growth of the fungus M. oryzae.

Taken together, these results indicate that small peptides, such as PAF104, regulate genes at the transcriptional level. Transcriptional control mediated by small interfering peptides (siP) affecting the functionality of specific transcription factors has been demonstrated (Lee and Mapp 2010; Seo et al. 2011; Yun et al. 2008). These siP share some properties of cell-penetrating peptides, such as their cationic charge and their ability to cross cellular membranes in a nondisruptive way and gain access to different cellular compartments. This translocation capability is being demonstrated for an increasing number of AMP (Henriques et al. 2006; Marcos et al. 2008). Although the cell-permeation properties of PAF104 remain to be demonstrated, the penetrating properties of the lead peptide PAF26 have been previously published (Muñoz et al. 2012).

The results presented here suggest that PAF104 could be a promising compound with potential application for the control of rice blast disease by blocking a specific target related to appressorium formation, a process essential for infection of rice leaves. It has been postulated that fungi are less likely to develop resistance against compounds that do not interfere with 
its vegetative growth (Thines et al. 2004). In addition to environment-friendly compounds, another restriction to applying a novel compound as a fungicide to control crop diseases is the fact that it must be economically viable for the farmer. One interesting advantage of the potential application of a peptide in plant protection is the ability to produce this compound in high amounts to reduce the cost of further application. The protein nature of PAF104 makes feasible the design of synthetic genes for its heterologous production through biotechnology. Moreover, a PAF104 specific inhibitory effect is also likely to be advantageous for developing new fungicides. The short sequence length of PAF104 favors structure and activity studies in a holistic approach to enhance their stability or to use as a lead compound to develop novel compounds with improved properties.

\section{MATERIALS AND METHODS}

\section{Strain and growing conditions.}

Two isolates of $M$. oryzae were used in this study for in vitro appressorium-inhibition assays, namely PR9 (CIRAD collection, Montpellier, France) and Guy11 (Centre for Plant Biotechnology and Genomics, Universidad Politécnica de Madrid, Spain). For the leaf- and root-infection assays, M. oryzae PR9 and Guy11 isolates that constitutively produce the GFP protein were used ( $g f p$-PR9 and $g f p$-Guy 11 ; provided by A. Sesma and B. San Segundo, respectively). The fungus was grown on oatmeal agar (Difco, Detroit) at $28^{\circ} \mathrm{C}$ under a $16-\mathrm{h}$ light and 8-h dark photoperiod. Conidia were collected from 11- to 13-day-old culture with sterile water, were filtered through miracloth, and were titrated with a Neubauer chamber.

\section{Synthetic peptides.}

Peptides (Table 1) were purchased at $>90 \%$ purity from GenScript Corporation (Piscataway, NJ, U.S.A.). They were synthesized by solid-phase methods using $N$-(9-fluorenyl)methoxycarbonyl chemistry. Stock solutions of each peptide were prepared in sterile milliQ-water, and peptide concentrations were determined by measuring the molar extinction coefficient (ع) at $280 \mathrm{~nm}$ for the Trp residue is $5,600 \mathrm{M}^{-1} \mathrm{~cm}^{-1}$ ).

\section{Appressorium formation inhibition assay.}

Development of appressoria in $M$. oryzae conidia was monitored on the hydrophobic surface of nontreated polystyrene 24well microtiter plates (Nunc, Thermo Fisher Scientific, Waltham, MA, U.S.A.). Drops $(8 \mu \mathrm{l})$ of a conidial suspension adjusted to $3 \times 10^{5}$ to $5 \times 10^{5}$ conidia per milliliter were placed on the hydrophobic surface and $2 \mu$ of peptides were then added to reach different final concentrations from $5 \times$ stock solutions. As positive control, the same volume of sterile water was added to some drops.

The plates were sealed and stored at $28^{\circ} \mathrm{C}$ in dark conditions. Pictures of five random fields for every drop were taken with an Olympus Stereoscope microscope SZX16 after 6 and $24 \mathrm{~h}$ of incubation, and the percentage of conidia induced to form appressorium was determined by microscopic examination of at least 100 conidia per replicate. The data were shown as the relative percentage of appressorium formed after peptide treatment compared with the appressoria formed in control samples. At least three independent experiments were carried out with each fungal isolate.

To identify possible sites of inhibition on appressorium formation, additional assays were conducted by the addition of known inductors for $M$. oryzae appressorium development. For that, we added $2.4 \mathrm{mM}$ cAMP (Sigma-Aldrich, St. Louis) or $10 \mu \mathrm{M}$ 1,16-hexadecanediol (Sigma-Aldrich), in order to evaluate the effect of these inductors on the inhibition activity of the peptide PAF104 after $6 \mathrm{~h}$ of incubation. In addition to the hydrophobic polystyrene plates mentioned above, we used cell-treated polystyrene plates (Costar, Corning Inc., Corning, NY, U.S.A.) as hydrophilic surface.

\section{RNA isolation and analysis} of gene expression by RT-qPCR.

Drops $(10 \mu \mathrm{l})$ of PR9 conidial suspension $\left(10^{6}\right.$ spores per milliliter) were incubated without or with $5 \mu \mathrm{M}$ and $20 \mu \mathrm{M}$ of PAF104 as described above on the hydrophobic surface of square polystyrene petri dishes (Deltalab, Barcelona, Spain). After $6 \mathrm{~h}$ of incubation, fungal material (about $2 \times 10^{6}$ conidia) was collected and immediately frozen in liquid nitrogen and lyophilized. RNA extraction was performed using the Maxwell 16 LEV simplyRNA purification kit (Promega, Madison, WI, U.S.A.). RNA quality was determined using an Agilent Bioanalyzer (Agilent Technologies, Santa Clara, CA, U.S.A.). RT-qPCR analyses were carried out in 96-well optical plates in a LightCycler 480 Real-Time PCR System (Roche) according to the following thermal profile: activation step $\left(95^{\circ} \mathrm{C}\right.$ for $\left.10 \mathrm{~min}\right)$, amplification step $\left(45\right.$ cycles of $95^{\circ} \mathrm{C}$ for $10 \mathrm{~s}, 60^{\circ} \mathrm{C}$ for $30 \mathrm{~s}$ ) and an additional cycle of dissociation curves to ensure a unique amplification. The reaction mixture contained $10 \mu \mathrm{l}$ of $2 \times \mathrm{SYBR}$ Green Master mix reagent (Roche Applied Science, Indianapolis, IN, U.S.A.), $2 \mu \mathrm{l}$ of cDNA sample, and $400 \mu \mathrm{M}$ of each gene-specific primer in a final volume of $20 \mu \mathrm{l}$. Three technical repeats of each one of at least three independent biological replicates were conducted. The elongation factor $1 \alpha$ was used in this assay as reference gene (Skamnioti and Gurr 2007). The relative expression software tool (Multiple Condition Solver RESTMCS v2) was used to determine the relative quantification of target genes normalized to the reference gene (Pfaffl et al. 2002).

\section{Conidia adhesion on polystyrene and germination assays.}

The effect of PAF104 on conidia adhesion was assayed as previously described but with minor modifications (Stanley et al. 2002). Briefly, the fungal conidia-peptide mixtures were prepared as described above on a hydrophobic surface, but the plates were incubated for $1 \mathrm{~h}$ at $28^{\circ} \mathrm{C}$ in dark conditions. After incubation, images of the different drops were taken with the Olympus Stereoscope microscope SZX16 under a 4× objective. After adding $1 \mathrm{ml}$ of distilled water to wash the nonadhered conidia, another set of images was taken. The number of conidia in each image was counted and the percent adhesion was calculated by dividing the number of conidia remaining after the wash by the number before washing.

To assess the influence of PAF104 on germination of $M$. oryzae, conidia suspensions $\left(10^{6}\right.$ conidia per milliliter $)$ were incubated with $20 \mu \mathrm{M}$ of PAF104 in a final volume of $10 \mu \mathrm{l}$. After a 4-h incubation at $28^{\circ} \mathrm{C}$, the percentage of conidia that had germinated was determined by direct microscopic counts.

\section{Growth inhibition assay.}

In vitro antifungal activity of the peptide PAF104 was determined using a microtiter plate assay as previously described (López-García et al. 2012a). The fungus was grown on sterile 96-well plate (Costar) in a final volume of $100 \mu \mathrm{l}$ of PDB (potato dextrose broth; Difco) diluted to half (50\% PDB), containing $0.003 \%$ (wt/vol) chloramphenicol to avoid bacterial growth. The assay mixture contained $40 \mu \mathrm{l}$ of a fungal suspension at $6 \times$ $10^{4}$ conidia per milliliter, $50 \mu \mathrm{l}$ of $\mathrm{PDB}$, and $10 \mu \mathrm{l}$ of a $10 \times$ peptide solution. As a control for fungal growth, $10 \mu \mathrm{l}$ of sterile milliQ-water was added to the mixture instead of peptide. The plate was incubated at $28^{\circ} \mathrm{C}$, and fungal growth was determined by measuring optical density at $492 \mathrm{~nm}$ in a SpectraMax M13 (Molecular Devices, Menlo Park, CA, U.S.A.) 
microplate reader. The mean and SD were calculated for each treatment. The experiment was repeated at least three times.

\section{Inoculation of rice leaves with $M$. oryzae conidia.}

The commercial japonica rice (Oryza sativa L.) cultivar Senia was used to evaluate appressorium formation on leaves. The rice plants were cultivated at $28^{\circ} \mathrm{C}$ under an 18 -h light and $6-\mathrm{h}$ dark photoperiod in the greenhouse. The second leaf of rice seedlings at the three-leaf stage was placed into plate dishes with $1 \%$ (wt/vol) bacto agar (Difco) containing $2 \mu \mathrm{g}$ of kinetin per milliliter.

The $M$. oryzae $g f p$-PR9 and $g f p$-Guy11 isolates were used for the leaf infection assay. Infection experiments were carried out using the detached leaf assay described by Coca and associates (2004) with minor modifications. Conidial suspensions at $1 \times 10^{6}$ to $5 \times 10^{6}$ conidia per milliliter were incubated with $20 \mu \mathrm{M}$ PAF104 or with sterile milliQ-water (for comparison purposes) for $30 \mathrm{~min}$. Tween-20 was added to the treated conidia for a final concentration of $0.025 \%$ (vol/vol). Drops $(10 \mu \mathrm{l})$ of the conidial suspension were placed onto detached leaves. Inoculated leaves were maintained in the dark in a chamber under high-humidity conditions at $28^{\circ} \mathrm{C}$ for $24 \mathrm{~h}$ and the drop was removed. Then, leaves were kept at $28^{\circ} \mathrm{C}$ and highhumidity conditions under a $16-\mathrm{h}$ photoperiod for the required time.

Rice leaves were subjected to CLSM analysis using a Leica SP5II spectral vertical confocal microscope at $6 \mathrm{~h}$ after inoculation with fungal conidia. Visualization of the $g f p$-expressing $M$. oryzae strains was carried out using excitation at $488 \mathrm{~nm}$ and emission at 505 to $530 \mathrm{~nm}$.

Disease symptoms were visualized after 3 days of inoculation. Pictures of the inoculated leaves were taken with a Nikon camera D7000. Leaf lesions were also observed by light and fluorescent microscopy, using an Olympus Stereoscope microscope SZX16. At least two independent experiments were carried out for each fungal isolate, and in each experiment, at least three leaves were inoculated. Lesion areas were quantified by Image Analysis Software, Assess 2.0, for plant disease quantification (Lamari 2008).

\section{Inoculation of rice roots with $M$. oryzae conidia.}

Infection studies of root tissues were done by direct application of $100-\mu$ conidia suspension at $10^{6}$ conidia per milliliter onto root tissues of 3-day-old seedlings. Inoculated seedlings were allowed to continue to grow for the required period of time. M. oryzae-infected roots were stained with propidium iodide $(0.2 \mathrm{~g} / \mathrm{ml})$ for $3 \mathrm{~min}$ and were subjected to CLSM analysis as previously described (Campos-Soriano and San Segundo 2009). Visualization of propidium iodide stained roots was carried out using excitation and emission at $543 \mathrm{~nm}$ and 560 to $615 \mathrm{~nm}$, respectively. Transverse sections of rice roots were made and microscopical examinations of the infected root were carried out at different times after inoculation.

\section{ACKNOWLEDGMENTS}

We thank M. Coca, B. San Segundo, and J. Marcos for their helpful comments during the course of this investigation and for their critical reading of the manuscript. The fungal strains used in this study were kindly provided by D. Tharreau from CIRAD, Montpellier, France (PR9 isolate), A. Sesma from Centre for Plant Biotechnology and Genomics, Universidad Politécnica de Madrid, Spain (GFP-Guy11 isolate), and B. San Segundo from CRAG, Barcelona (GFP-PR9 isolate). The PAF peptides were kindly provided by J. F. Marcos from IATA, CSIC, Spain. B. LópezGarcía is a recipient of a research contract from the 'Ramón y Cajal' program (MICINN, Spain). This work was supported by grant AGL201016847 from the Ministerio de Ciencia e Innovación (MICINN, Spain). We thank the Generalitat de Catalunya (Xarxa de Referencia en Biotecnología and SGR 09626) for substantial support.

\section{LITERATURE CITED}

Avila-Adame, C., and Koller, W. 2003. Characterization of spontaneous mutants of Magnaporthe grisea expressing stable resistance to the Qoinhibiting fungicide azoxystrobin. Curr. Genet. 42:332-338.

Brent, K. J., and Hollomon, D. W. 2007. Fungicide resistance in crop pathogens: How can it be managed? FRAC Monograph No. 1. 2nd revised ed. Fungicide Resistance Action Committee, Brussels, Belgium.

Campos-Soriano, L., and San Segundo, B. 2009. Assessment of blast disease resistance in transgenic PRms rice using a $g f p$-expressing Magnaporthe oryzae strain. Plant Pathol. 58:677-689.

Carmona, L., Gandía, M., López-García, B., and Marcos, J. F. 2012. Sensitivity of Saccharomyces cerevisiae to the cell-penetrating antifungal peptide PAF26 correlates with endogenous nitric oxide (NO) production. Biochem. Biophys. Res. Commun. 417:56-61.

Coca, M., Bortolotti, C., Rufat, M., Peñas, G., Eritja, R., Tharreau, D., Martínez del Pozo, A., Messeguer, J., and San Segundo, B. 2004. Transgenic rice plants expressing the antifungal AFP protein from Aspergillus giganteus show enhanced resistance to the rice blast fungus Magnaporthe grisea. Plant Mol. Biol. 54:245-259.

Dean, R., van Kan, J. A. L., Pretorius, Z. A., Hammond-Kosack, K. E., Di Pietro, A., Spanu, P. D., Rudd, J. J., Dickman, M., Kahmann, R., Ellis, J., and Foster, G. D. 2012. The Top 10 fungal pathogens in molecular plant pathology. Mol. Plant Pathol. 13:414-430.

DeZwaan, T. M., Carroll, A. M., Valent, B., and Sweigard, J. A. 1999. Magnaporthe grisea Pth11p is a novel plasma membrane protein that mediates appressorium differentiation in response to inductive substrates cues. Plant Cell 11:2013-2030.

Ebbole, D. J. 2007. Magnaporthe as a model for understanding host-pathogen interactions. Annu. Rev. Phytopathol. 45:437-456.

Hamel, L-P., Nicole, M-C., Duplessis, S., and Ellis, B. E. 2012 Mitogenactivated protein kinase signaling in plant-interacting fungi: Distinct messages from conserved messengers. Plant Cell 24:1327-1351.

Hancock, R. E. W., and Sahl, H. G. 2006. Antimicrobial and host-defense peptides as new anti-infective therapeutic strategies. Nat. Biotechnol. 24:1551-1557.

Henriques, S. T., Melo, M. N., Castanho, M. A. R. B. 2006. Cell-penetratin peptides and antimicrobial peptides: How different are they? Biochem. J. 399:1-7.

Jin, Q., Li, C., Li, Y., Shang, J., Li, D., Chen, B., Dong, H. 2013. Complexity of roles and regulation of the PMK1-MAPK pathway in mycelium development, conidiation and appressorium formation in Magnaporthe oryzae. Gene Expr. Patterns 13:133-141.

Kawahara, Y., Oono, Y., Kanamori, H., Matsumoto, T., Itoh, T., and Minami, E. 2012. Simultaneous RNA-Seq Analysis of a Mixed Transcriptome of Rice and Blast Fungus Interaction. PloS One 7:e49423. Published online.

Khang, C. H., Berruyer, R., Giraldo, M. C., Kankanala, P., Park, S.-Y., Czymmek, K., Kang, S., and Valent, B. 2010. Translocation of Magnaporthe oryzae effectors into rice cells and their subsequent cell-to-cell movement. Plant Cell 22:1388-1403.

Knight, S. C., Anthony, V. M., Brady, A. M., Greenland, A. J., Heaney, S. P., Murray, D. C., Powell, K. A., Schulz, M. A., Spinks, C. A., Worthington, P. A., and Youle, D. 1997. Rationale and perspectives on the development of fungicides. Annu. Rev. Phytopathol. 35:349-372.

Kong, L-A., Li, G.-T., Liu, Y., Liu, M.-G., Zhang, S.-J., Yang, J., Zhou, X.Y., Peng, Y.-L., Xu, J.-R. 2013. Differences between appressoria formed by germ tubes and appressorium-like structures developed by hyphal tips in Magnaporthe oryzae. Fungal Genet. Biol. 56:33-41.

Lamari, L. 2008. Assess 2.0: Image Analysis Software for Plant Disease Quantification. APS Press, St. Paul, MN, U.S.A.

Lanver D., Mendoza-Mendoza, A., Brachmann, A., and Kahmann, R. 2010. Sho1 and Msb2-related proteins regulate appressorium development in the smut fungus Ustilago maydis. Plant Cell 22:2085-2101.

Lee, L. W., and Mapp, A. K. 2010. Transcriptional switches: Chemical approaches to gene regulation. J. Biol. Chem. 258:11033-11038.

Lengeler, K. B., Davidson, R. C., D'Souza, C., Harashima, T., Shen, W.C., Wang, P., Pan, X., Waugh, M., and Heitman, J. 2000. Signal transduction cascades regulating fungal development and virulence. Microbiol. Mol. Biol. Rev. 64:746-785.

Liu, J. L., Wang, X. J., Mitchell, T., Hu, Y. J., Liu, X. L., Dai, L. Y., and Wang, G. L. 2010. Recent progress and understanding of the molecular mechanisms of the rice-Magnaporthe oryzae interaction. Mol. Plant Pathol. 11:419-427.

Liu, W. D., Zhou, X. Y., Li, G. T., Li, L., Kong, L. G., Wang, C. F., Zhang, H. F., and Xu, J. R. 2011. Multiple plant surface signals are sensed by different mechanisms in the rice blast fungus for appressorium formation. PloS Pathog. 7:e1001261. Published online.

López-García, B., González-Candelas, L., Pérez-Payá, E., and Marcos, J. F. 2000. Identification and characterization of a hexapeptide with activ- 
ity against phytopathogenic fungi that cause postharvest decay in fruits. Mol. Plant-Microbe Interact. 13:837-846.

López-García, B., Pérez-Payá, E., and Marcos, J. F. 2002. Identification of novel hexapeptides bioactive against phytopathogenic fungi through screening of a synthetic peptide combinatorial library. Appl. Environ. Microbiol. 68:2453-2460.

López-García, B., Ubhayasekera, W., Gallo, R. L., and Marcos, J. F. 2007. Parallel evaluation of antimicrobial peptides derived from the synthetic PAF26 and the human LL37. Biochem. Biophys. Res. Commun. 356:107-113.

López-García, B., Gandia, M., Muñoz, A., Carmona, L., and Marcos, J. F. 2010. A genomic approach highlights common and diverse effects and determinants of susceptibility on the yeast Saccharomyces cerevisiae exposed to distinct antimicrobial peptides. BMC Microbiol. 10:289-305.

López-García, B., Hernández, M., and San Segundo, B. 2012a. Bromelain, a cysteine protease from pineapple (Ananas comosus) stem, is an inhibitor of fungal plant pathogens. Lett. Appl. Microbiol. 55:62-67.

López-García, B., San Segundo, B., and Coca, M. 2012b. Antimicrobial peptides as a promising alternative for plant disease protection. Pages 263-294 in: Small Wonders: Peptides for Disease Control. K. Rajasekaran, J. W. Cary, J. M. Jaynes, and E. Montesinos, eds. American Chemical Society, Washington, DC.

Marcos, J. F., Muñoz, A., Pérez-Payá, E., Misra, S., and López-García, B. 2008. Identification and rational design of novel antimicrobial peptides for plant protection. Annu. Rev. Phytopathol. 46:273-301.

Mathioni, S., Belo, A., Rizzo, C., Dean, R., and Donofrio, N. 2011. Transcriptome profiling of the rice blast fungus during invasive plant infection and in vitro stresses. BMC Genomics 12:49-68.

Montesinos, E., Badosa, E., Cabrefiga, J., Planas, M., Feliu, L., and Bardaji, E. 2012. Antimicrobial peptides for plant disease control. from discovery to application. Pages 235-261 in: Small Wonders: Peptides for Disease Control. K. Rajasekaran, J. W. Cary, J. M. Jaynes, and E. Montesinos, eds. American Chemical Society, Washington, DC.

Muñoz, A., López-García, B., Pérez-Payá, E., and Marcos, J. F. 2007. Antimicrobial properties of derivatives of the cationic tryptophan-rich hexapeptide PAF26. Biochem. Biophys. Res. Commun. 354:172-177.

Muñoz, A., Gandía, M., Harries, E., Carmona, L., Read, N. D., and Marcos, J. F. 2012. Understanding the mechanism of action of cell-penetrating antifungal peptides using the rationally designed hexapeptide PAF26 as a model. Fungal Biol. Rev. 26:146-155.

Oh, H. S., and Lee, Y. H. 2000. A target-site-specific screening system for antifungal compounds on appressorium formation in Magnaporthe grisea. Phytopathology 90:1162-1168.

Pfaffl, M. W., Horgan, G. W., and Dempfle, L. 2002. Relative expression software tool (RESTC) for group-wise comparison and statistical analysis of relative expression results in real-time PCR. Nucleic Acids Res 30:e36. Published online.

Ragsdale, N. N. 2000. The impact of the food quality protection act on the future of plant disease management. Annu. Rev. Phytopathol. 38:577596.

Seo, P. J., Hong, S. Y., Kim, S-G., and Park, C-M. 2011. Competitive inhibition of transcription factors by small interfering peptides. Trends Plant Sci. 16:541-549.
Sesma, A., and Osbourn, A. E. 2004. The rice leaf blast pathogen undergoes developmental processes typical of root-infecting fungi. Nature 431:582-586.

Skamnioti, P., and Gurr, S. J. 2007. Magnaporthe grisea Cutinase 2 mediates appressorium differentiation and host penetration and is required for full virulence. Plant Cell 19:2674-2689.

Soanes, D. M., Chakrabarti, A., Paszkiewicz, K. H., Dawe, A. L., and Talbot, N. J. 2012. Genome-wide transcriptional profiling of appressorium development by the rice blast fungus Magnaporthe oryzae. PLoS Pathog. 8:e1002514. Published online.

Stanley, M. S., Callow, M. E., Perry, R., Alberte, R. S., Smith, R., and Callow, J. A. 2002. Inhibition of fungal spore adhesion by zosteric acid as the basis for a novel, nontoxic crop protection technology. Phytopathology 92:378-383.

Takagaki, M., Kaku, L, Watanabe, S., Kawai, K., Shimizu, T., Sawada, H., Kumakura, K., Nagayama, K. 2004. Mechanism of resistance to carpropamid in Magnaporthe grisea. Pest Manag. Sci. 60:921-926.

Talbot, N. J., Ebbole, D. J., Hamer, J. E. 1993. Identification and characterization of MPG1, a gene involved in pathogenicity from the rice blast fungus Magnaporthe grisea. Plant Cell 5:1575-1590.

Thines, E., Anke, H., and Weber, R. W. S. 2004. Fungal secondary metabolites as inhibitors of infection-related morphogenesis in phytopathogenic fungi. Mycol. Res. 108:14-25.

Tucker, S. L., Besi, M. I., Galhano, R., Franceschetti, M., Goetz, S., Lenhert, S., Osbourn, A., and Sesma, A. 2010. Common Genetic pathways regulate organ-specific infection-related development in the rice blast fungus. Plant Cell 22:953-972.

Wang, G.-L., and Valent, B. 2009. Advances in Genetics, Genomics and Control of Rice Blast Disease. Springer Science and Business Media, New York.

Wilson, R. A., and Talbot, N. J. 2009. Under pressure: Investigating the biology of plant infection by Magnaporthe oryzae. Nat. Rev. Microbiol. 7:185-195.

$\mathrm{Xu}, \mathrm{J}-\mathrm{R} .$, Staiger, C.J., and Hamer, J. E. 1998. Inactivation of the mitogenactivated protein kinase $M p s 1$ from the rice blast fungus prevents penetration of host cells but allows activation of plant defense responses. Proc. Natl. Acad. Sci. U.S.A. 95:12713-12718.

Yun, J., Kim, S-G., Hong, S., and Park, C-M. 2008. Small interfering peptides as a novel way of transcriptional control. Plant Signal. Behav. 3:615-617.

Zasloff, M. 2002. Antimicrobial peptides of multicellular organisms. Nature 415:389-395

Zhao, X., Kim, Y., Park, G., and Xu, J-R. 2005. A mitogen-activated protein kinase cascade regulating infection-related morphogenesis in Magnaporthe grisea. Plant Cell 17:1317-1329.

\section{AUTHOR-RECOMMENDED INTERNET RESOURCES}

The Center for Health and Wellness website: www.fda.org European Food Safety Authority: www.efsa.europe.eu Fungicide Resistance Action Committee website: www.frac.info United States Environmental Protection Agency: www.epa.gov 